\title{
PSYCHOLOGICAL FEATURES OF FEARS \\ IN OLDER PRESCHOOL CHILDREN \\ WITH MENTAL DEVELOPMENTAL DELAY
}

\section{Panov M. S., Zhadlenko I. O.}

\section{INTRODUCTION}

The relevance of our study is due to the need to establish productive psychological and pedagogical interaction between the subjects responsible for the successful development of the child in the early stages of its ontogenesis, in order to promote a happy, self-sufficient, socially successful personality. In addition, this, as is well known, depends on the quality of the social situation of the child's development - and the younger the child, the more it depends on the situation of development, which creates for him the immediate environment. For a senior preschooler, this environment is primarily his family, as well as the preschool educational institution (if the child attends such an institution and, accordingly, is included in the scope of its pedagogical and educational influence).

Fears have a special place in the life experience of a child who begins to master the world around him and his place in it. Fear is important for the development of the child, is an important link in the regulation of its social contacts and behavior, if it accurately performs its functions. Thus, there are three main functions of fear: 1) mobilization (mobilizes human forces for active activities in critical situations); 2) warning (helps to better remember dangerous and unpleasant events); 3) strategic (occurs when information is not enough to make a comprehensive decision, fear dictates the strategy of behavior).

Since fear is a natural emotion, the means of its processing by a child are just as natural. However, under certain conditions, a child with mental retardation may not be able to cope with age (natural) fear, and then the natural fear can be transformed into pathological. Pathological fear no longer protects the child, but prevents his communication with the environment, his mental and personal development, leads to psychosomatic diseases. The modern child with mental developmental delay is under the constant influence of the mediatized environment, 
which is not always positive. As a result, she has to deal with new types of fears caused by movies with elements of violence and horror, computer game characters, reports of murders and terrorist acts in the media. Thus, this category of children's fears and opportunities for successful treatment, in particular overcoming them by children requires more in-depth, detailed, comprehensive research. In addition, the analysis of a large number of works on this issue has shown that many scientific generalizations on this issue are quite ambiguous, ambivalent or contradictory, and therefore require additional, empirical research that would demonstrate the objectivity and retest reliability of currently known scientific data in this area.

\section{Scientific ideas about fear as emotion and experience}

The modern social environment in which the development of an older preschool child with mental retardation takes place is filled with many risks, threats, dangers caused by the aggressiveness of society. Preschoolers have free access to information about hostilities, deaths, wounds, terrorist acts, manufactured disasters, natural disasters. Heroes of modern cartoons and computer games are mostly characterized by sinister appearance and cruelty. Complicating the situation is excessive material stratification of the population, uncertainty of prospects and emotional tension of adults and lack of time, formalization of relations, strict regulation of life, constant haste ${ }^{1}$. The combination of all these reasons leads to the emergence of older preschool children with mental retardation of fears, which negatively affects the formation of personality in general.

As the analysis of the professional literature shows, there is no classification of emotions that would be adopted unanimously by all researchers. Some scientists acknowledge the existence of basic emotions, others deny, preferring to see in emotions only the function of perceptual-cognitive processes.

Proponents of social theories of emotion, in turn, believe that they are a product of culture, socialization and learning, personal and social experience and that a person produces and constructs emotions based directly on their own life experience. According to them, a person produces emotions in the required amount depending on the needs of the

${ }^{1}$ Assessment of behavioral and emotional problems in infancy: a systematic review / D. Bagner et al. Clinical Child and Family Psychology Review. 2012. P. 113-128. 
situation and their own capabilities. One way or another, emotions retain a sign of them as the basic formation of the psyche of highly organized living beings, and above all - man.

In natural design, fear is an emotion that arises in situations of threat to the biological or social existence of the individual and is aimed at the source of real or imagined danger. Fear can be considered as a special and specific emotion that deserves to be allocated to a separate category ${ }^{2}$. Unlike other unpleasant psychophysiological experiences that can be caused by the real action of life-threatening and well-being factors, fear arises not only in the face of these factors, but also in their prediction, the assumption that they are possible (phantom fear). Depending on the nature of the threat, the intensity and specificity of the experience of fear varies in a wide range of shades (fear, fright, horror, etc.). Weak fear can be experienced as an anxious premonition, anxiety. As fear grows, a person feels more and more insecure about their own safety, a threat to the physical and / or mental "I", and in extreme cases - a threat to life. Intense fear is experienced as a feeling of absolute insecurity, a feeling that the situation is out of control ("the earth is out of control").

A person may experience fear in different situations, but all these situations have one thing in common. They are experienced, perceived by a person as situations in which his peace and well-being are threatened. The subjective experience of fear is horrible, it can make a person numb, leading him to a completely helpless state, or, conversely, can make him run away from danger. Moreover, as already mentioned, this experience often has a real source.

The specific relationship between arousal and fear or surprise and fear can be the result of learning. In the process of learning a person and gaining emotional experience, any emotions can become activators of fear. In addition, fear itself is an activator. By experiencing fear and expressing it in behavior, a person receives feedback from their own emotional expression, and this can increase their fear. In this case, the very experience of fear frightens a person.

The most reliable and accurate indicators of fear are facial expressions. With a detailed facial expression of fear, the eyebrows are raised and slightly reduced to the bridge of the nose, resulting in horizontal wrinkles in the center of the forehead deeper than the sides.

\footnotetext{
${ }^{2}$ Gurnani T., Ivanov I., Newcorn J. Pharmacotherapy of Aggression in Child and Adolescent Psychiatric Disorders. Journal of Child Adolescent Psychopharmacology. 2016. P. 65-73.
} 
The eyes are wide open, the upper eyelid is sometimes slightly raised, because of which the whites of the eye between the eyelid and the pupil are exposed. The corners of the mouth are sharply extended, the mouth is usually open. However, in the process of growing up and socializing, the manifestations of fear are modified and largely begin to be controlled and hidden by man. Therefore, its obvious natural manifestations can be observed less often. Facial expressions of fear are possible only in conditions of sudden threat and / or intense stimulation.

Fear is an extremely strong emotion; it significantly affects the perceptual-cognitive processes and behavior of the individual. When a person feels fear, his attention sharply narrows, focusing on the object or situation that signals danger. Intense fear creates the effect of «tunnel perception», namely significantly limits the perception, thinking and freedom of choice of the individual. In addition, fear restricts a person's freedom of behavior. We can say that in a situation of fear a person ceases to belong to himself, he moves by a single desire - to eliminate the threat, to avoid danger. This effect can have adaptive and protective value. If the fear is justified, then a certain narrowing of perception and restriction of freedom are not only justified but also necessary.

\section{Psychological features of fears of older preschool children with mental developmental delay}

Analyzing the phenomenon of fear, scientists write that the fear of objects that have caused pain is useful because it encourages future avoidance of these objects; experience because of memory and the pain itself would simply deprive the activity of avoiding any meaning.

Recently, the question of the importance of the emotion of fear for a person has become relevant in the context of discussions about the possible impact on the psyche of viewers of television products that contain elements of screen violence and horror. In addition, if researchers are unanimous about screen violence and they, in particular, have identified new types of fears inspired by children's screen media, then the situation is not so clear about horror films ${ }^{3}$. Recently, and there are many reasons to link this with the medialization of the social space of modern man's life, the problem of fear has been activated in psychological research and in everyday discourse. There are many

${ }^{3}$ Hong J., Tillman R., Luby J. Disruptive behavior in preschool children: distinguishing normal misbehavior from markers of current and later childhood conduct disorder. Journal of Pediatrics. 2015. P. 723-730. 
assumptions about the emergence of new types of fears due to new realities of life, which were previously recorded less often.

About a quarter of children with mental developmental delay, have signs of increased anxiety compared to the norms set for their age groups. Preschool children with mental retardation showed a much higher level of fear of blood and unexpected sharp sounds compared to the age norm. In addition, boys showed a higher level of fear of death compared to the age norm, and girls - a fear of pain compared to the norm.

The analysis of children's drawings showed that the predominance of unconstructive reactions (open aggression, accusations of other people, lack of active coping strategies) to negative situations exceeds the norm in $34 \%$ of children with mental developmental delay aged 6-7 years. Such data encourage researchers to try to review fear assessments, describe new fears, and develop preventive measures to prevent them.

The study found that children with mental developmental delay received information about current events from the media, from adults, as well as from their own negative experiences. According to the results of this study, we can identify the main sources of activation of fears in Ukrainian preschoolers in today's conditions:

1) the influence of the media, in particular television;

2) the transfer of fears from people from the immediate environment.

Preschool age is the age when fears are most motivated by emotions and are temporary. However, traumatic situations similar to those experienced in the past, or at least the threat of recurrence, can revive stored fears that may reappear. Over time, such fears can become more intense, become pathological and accompany a person throughout life, if not provided with adequate psychological assistance in time.

The next source is the influence of the media. Speaking of the modern world, it is difficult to avoid the topic of media - the media (traditionally this includes the press, press, television, cinema, radio, sound recording and the Internet). The media have become especially important in the life of humankind over the last half century. Media today is one of the most important areas in the lives of people around the world ${ }^{4}$.

A special place in the development of the child's psyche can be given to films and television, because the modern child, whether we like it or not, falls under their influence. The most pressing issue is the possible consequences of the population's consumption of television information

${ }^{4}$ Kolko D., Perrin E. The integration of behavioral health interventions in children's health care: services, science, and suggestions. Journal of Clinical Child and Adolescent Psychology. 2014. P. 216-228. 
with elements of violence and horror, such that they have an extremely destructive effect on the psyche and behavior of viewers.

Parents, who usually do not have a culture of watching TV, are not able to control the time of watching children with mental developmental delay and their content. Quite common are situations where the mother breastfeeds the baby with the TV on or preschoolers eat, play and even fall asleep to the sounds of the TV. Children witness many unwanted events on the screen (for example, scenes of violence, reports of terrorist acts, wars, the consequences of natural disasters, epidemics, etc.), which traumatize the psyche of children, activate their fear and anxiety. Naturally, a large amount of information coming from the screen is consumed and remembered by a child with mental developmental delay, often bypassing his consciousness.

Most children with mental developmental delay go through a number of age periods of hypersensitivity to certain fears, which are transmitted to children in the process of direct communication in the family and resonate with the fears of parents. This is the most typical way of transmitting fears; the appearance of fears in children is more likely than their parents, especially if there is close emotional contact between them. As a rule, fears are transmitted to children unconsciously. Mothers, due to close biological and emotional contact with the child, instinctively seek to protect it from the recurrence of their fears, but this is what they draw special attention to the danger that underlies a particular fear.

Thus, we can assume that the fears of modern preschool children with mental developmental delay are somewhat different from the fears experienced by children two or three decades ago, because they reflect changes in the socio-cultural, economic and political life of society.

Complications and expansion of educational programs, "computerization", daily reports on armed conflicts, catastrophes, destruction, disasters broadcast on television, horror films, militants, criminogenic situation - all this forms a new psychological reality in the minds of modern children. The current situation causes mental stress, which is usually manifested in such emotional states and experiences of children as anxiety and fear. In addition, it is not so much these experiences as the results of the treatment of these conditions and their consequences, and especially the systematic recurrence of negative consequences, form in a child with mental developmental delay "learned helplessness syndrome" and significantly affect his personal and social development.

Emotional saturation and dynamics of life in modern society lead to high psychological stress not only in adults but also in children. These circumstances are largely due to changes in society, increasing demands 
on his part to the intellectual, psycho-emotional, physical capabilities of the child with mental developmental delay, to his ability to regulate in socially acceptable ways emotional states 5 . Without proper psychological support for adults, preschoolers in these conditions are too difficult, because both the child's body and psyche are still unstable, and therefore are very conducive to environmental influences: insecurity and insecurity of the child's own well-being cause her anxiety and fears. Today, more and more children with mental developmental delay have emotional problems, are in a state of affective tension due to a constant feeling of insecurity, lack of support in the immediate environment and helplessness.

\section{Psychological resources of older preschool children with mental developmental delay in processing fears}

Resources of psychological protection are actualized by means of the corresponding mechanisms. As is known from the works of well-known representatives of the school of psychoanalysis, the mechanisms of psychological protection involuntarily, automatically «turn on» and function in the daily experience of a person who objectively or subjectively feels in danger, while remaining a determinant or motive of behavior hidden from himself, and from outside observers. Protective behavior initiated by the action of psychological defense mechanisms is a rather ambiguous phenomenon. It can not only look, but also in fact (according to the results) be quite appropriate and contribute to the psychological stabilization of those who experience fear. However, such behavior, even if outwardly perceived as appropriate, can actually lead to the disorganization of a person who is under the influence of fear. In this case, the term «behavior» is used in a broad sense, because in reality such behavior is not only specific actions, but also other manifestations, including cognitive and emotional nature.

In the modern psychological literature, there are different definitions of protection phenomena. In a broad sense, protection is a concept that characterizes any reaction of the body in order to preserve itself and its integrity. In medicine, for example, a variety of protective reactions to disease resistance (body resistance) or protective reflexes of the body are well known, such as reflex blinking as a reaction to an object approaching quickly or removing the hand from a hot surface. In the professional literature on pedagogical, age, social and special

${ }^{5}$ Ramsawh H., Chavira D., Stein M. Burden of anxiety disorders in pediatric medical settings: prevalence, phenomenology, and a research agenda. Archives of pediatrics and adolescent medicine. 2010. P. 965-972. 
psychology, the most common terms used to describe such phenomena from the spectrum of "psychological protection" as protective mechanisms, protective reactions, protective strategies, neurotic defenses, protective personality traits, protective behavior. In addition, the now well-known phenomenon of perceptual protection, which consists in excessively raising the thresholds of perception of «taboo», namely forbidden to discuss words, objects, situations, has been experimentally revealed.

The term "protective mechanism" refers to a strong behavioral protective pattern (scheme, stereotype, model), formed to protect the "I" from awareness of the phenomena that cause anxiety. The term "behavioral" needs further clarification here. For some authors, it means outwardly visible patterns of thought, thought, or action that function as detours, as an avoidance of anxiety, or as transformers of what generates anxiety. This view is more typical of psychologists and psychiatrists of non-psychoanalytic orientation, who, however, recognize the unconscious nature of defense mechanisms. For other authors, who adhere to a psychoanalytic understanding of the nature of protective mechanisms, outwardly visible types of protective behavior are only external, sometimes even private manifestations of internal, hidden, intrapsychic process, which is just a true protective mechanism.

According to representatives of the psychodynamic direction in psychology, fear-activated defense mechanisms are inherited. They are activated at certain stages of human development in certain life situations and, thanks to them; a person reacts in a protective way to those situations that qualify his brain as comfortable, dangerous and threatening.

In the modern psychological literature, psychological protection is usually considered to be any reactions that are in a person's experience and to which he resorts - in particular and unconsciously, intuitively - in order to protect their own internal mental structures, their "I" in potentially dangerous or threatening situations. These reactions and mechanisms that are "switched on" are specific to each age period of human life, but their ultimate goal, as has been repeatedly noted, is to reduce traumatic feelings, discomfort, psychological stress caused by fear.

Fear is a basic human emotion necessary for the formation and normal development of his psyche and successful socialization. At different ages of human life, fear performs a number of important psychological functions: mobilization; warning; protective; socializing; strategic, etc.

Psychological features of fears of older preschoolers with mental developmental delay are primarily as follows: 
1) most of these fears are natural and temporary;

2) their content is due to the age of the child;

3 ) the main sources of children's age fears are the nature of the child as a human being and the social environment in which he grows up;

4) with the actualization of age fears, the relevant mechanisms and strategies of their processing are automatically actualized, which at the very beginning have an involuntary and intuitive nature and are strategies of "common sense".

Typical age fears of older preschool children with mental retardation include:

1) archaic;

2) existential;

3) congratulatory fears;

4) fears of a phobic nature (which are somehow related to the protection and preservation of life);

5) fears that arise from the social nature of man and are related to basic social needs, which are activated in older preschool age.

A special and to some extent "artificial" kind of fears of modern children are the so-called media fears, or fears activated by screen media. Unlike children's natural fears (which are able to initiate themselves, live relatively successfully as a child and disappear without special intervention), media fears require special attention from adults.

Along with the natural age fears, a person, in particular a senior preschooler with mental developmental delay has adequate psychological resources for their processing, which can be divided into two main groups:

1) protection resources and relevant mechanisms and strategies for their implementation;

2) coping resources and appropriate mechanisms and strategies for active processing of fear, or coping strategies (behavioral, cognitive and emotional).

Psychological protection and coping perform similar functions - they help a person at all ages of his life in dangerous, life threatening and well-being situations. However, protection strategies are a way to avoid and procrastinate, and coping strategies are to actively engage in circumstances, live productively, and gain new experiences. The peculiarity of coping strategies of older preschool children with mental developmental delay is not as relevant as their potential understanding, which is in the zone of their immediate development. The implementation of these strategies involves not so much rational as intuitive factors, the effectiveness of which is primarily explained not by considerations of logic, but by considerations of "intuitive expediency". 


\section{Spectra of fears of older preschoolers with mental developmental delay through the eyes of children themselves}

Our study is implemented in three stages.

The first step is to objectify the problem of children's fear. The purpose of the stage is an empirical study and analysis of the range of fears and their sources and features of response of older preschoolers with mental developmental delay (basic methods: individual conversations with children, conversations on projective drawings, projective method "Fears in houses").

The second is the stage of empirical research, and qualitative analysis and definition of strategies for overcoming fear by older preschoolers with mental developmental delay. The purpose of the stage is empirical research and analysis of strategies of response of older preschoolers with mental developmental delay to objects and situations that cause fear (basic methods: conversation with children, observation, interviews with pictures, questionnaires of parents, interpretation).

The third stage is an empirical study of the characteristics of groups of children with mental developmental delay who use different types of strategies for dealing with age fears - protection strategies (such as unproductive coping) and coping strategies (productive coping). The purpose of the stage is to identify personal, emotional and behavioral differences of children with mental developmental delay.

The study involved 1) older preschoolers with mental developmental delay; 32 of them are girls and 25 are boys; 2) their parents - as participants in the survey who agreed to participate in the study and agreed to participate in it their children. Criteria for selecting participants for the study were: 1) age of the child (6-7 years), 2) consent to participate in the study of parents and children themselves.

As it was found out through individual conversations with children in everyday communication with them and in the process of working with projective drawings, typical fears of older preschoolers with mental developmental delay are fears for their lives, based on self-preservation instinct (these fears are known in the professional literature as existential, living, archaic) - these fears are verbalized by children most actively (74\%): fear of darkness, animals, elements, fire, water, attacks, war, blood, injections, doctors, fear of getting sick, etc.; fear of unknown, fictional characters (including screen characters), nightmares, loneliness, etc.; fear of death, death of parents, etc.

In addition to the above, the second group of children's fears, which is much less represented, are the so-called social fears: fear of being punished, fear of not meeting the requirements of parents, to be negatively assessed (26\%). 
Thus, in the space of describing their own fears by older preschoolers with mental developmental delay, two main groups of these fears are distinguished:

1) fears for the preservation of life, which are based on the instinct of self-preservation (archaic, vital and existential);

2) social fears - as a psychological neoplasm of older preschool age, the appearance of which marks the beginning of the formation of social readiness of the child to enter a wider social environment, outside the family and preschool.

The next stage in identifying the spectra of children's fears was the stage of projective diagnosis. In particular, the projective method "My fears" was used to update other, undiscovered at the stage of conversations, types of children's fears and objects that activate these fears. At the beginning, with the help of an introductory conversation, older preschool child preschoolers with mental developmental delay was asked to remember some objects or situations that cause him fear. The child was then asked to draw what she feared most. To do this, she received a white sheet of A-4 paper and colored pencils.

At the end of the drawing, the child was asked to tell what she had drawn, that is, the child had to verbalize his fear. When analyzing the drawings, attention was paid to what the child drew, how the drawing was arranged on a sheet of paper, as well as the colors she used in the drawing process, the pressure of the pencil, the neatness of the lines, the size of the object, and so on.

Their parents were also involved in the study of the spectrum of children's fears. This made it possible to compare the results of the study of children and parents and finally to find out how well parents are aware of their own children's fears and how competently they behave in situations where the child shows his fear or needs help and support. To do this, we have developed a questionnaire containing a number of questions, including the questions "What usually causes fear in your child?", "What is your child most afraid of?", "How does it usually turn out?" and other.

An analysis of parents' responses to open-ended questionnaires revealed how adults generally relate to their children's fears, how often their children show and express fear, and how they do it, what children are most afraid of, how they behave when frightened (for observations of the parents themselves), how competently adults provide assistance to children in such situations. Below are some survey results.

Analysis of parents' answers to the question "Do you think it is normal that your child has fears?" $57,9 \%$ of respondents answered "yes, it' natural", $28,9 \%$ were hesitant to answer, and $13,2 \%$ of surveyed 
parents believe that children's fears are "not normal". Thus, at least a third of parents do not have a clear idea of children's fears and their role in the child's life, and therefore, we can assume that these parents are the "risk group" to which should be directed appropriate psychological and pedagogical educational work of special preschool specialists. Institutions. It is also possible to assume that at least each of the 10 parents has some problems in working with their own child to overcome their age-related childhood fears (and, as further answers from parents show, this figure is not decreasing, but rather increasing).

To the question "How often do you notice that your child is afraid of something?" $39,5 \%$ of surveyed parents stated that they notice this "very rarely" and that this issue is not relevant to them; $42,1 \%$ of them answered "sometimes I notice" and 18,4\% of the surveyed parents admitted that this question is relevant for them, because they notice the fixed fears of their children "quite often" and it causes them concern. Thus, summarizing parents' answers to the first two questions of the questionnaire, we can talk about one "risk group" among parents who raise older preschoolers with mental developmental delay - namely parents who observe certain problems of their child in processing fears and do not realize how in these situations to do.

Thus, the analysis of the results of the projective study "Fears in the houses" gives grounds to say that:

1) the presence of natural age fears is characteristic of the vast majority of older preschool children with mental developmental delay, and children are quite able to talk about them, but - due to the peculiarities of visual thinking of older preschoolers with mental developmental delay - these fears are much better explained time of individual conversations with children, as in the process of projective drawing, work with a series of projective drawings and the use of other projective research methods;

2) the spectra and extent of natural age fears and their quantitative ratio change with the changing social and informational situation in society (yes, some of the typical fears of children, which were recorded, for example, 20 years ago, have lost their relevance for today's children, including older preschoolers with mental developmental delay);

3 ) for today's older preschoolers with mental developmental delay, the existential fear of death is inferior to the fear of violent death (on the one hand - through war and hostilities, criminal actions of antisocial individuals, terrorism, robbery, robbery, kidnapping by criminals, etc., and on the other - because of terrible virtual monsters, monsters, unnaturally large and amazing animals, spiders, birds, etc.); 
4) greater share among children's fears (compared to children of the last millennium) are acquired social fears (primarily fear of rejection, fear of inconsistency, fear of being helpless);

5) so-called "media" fears, namely fears actualized by the media, are gradually expressed and gain weight.

An empirical study of the natural age fears of older preschoolers with mental developmental delay was conducted in three stages: 1) the stage of objectification of the problem of children's fear (its purpose is an empirical study and analysis of the range of fears and features of their experience by children of older preschool age with mental retardation); 2 ) the stage of identifying and defining strategies for overcoming fear by older preschoolers with mental developmental delay (the purpose of the stage is empirical research and analysis of strategies of response of older preschoolers with mental developmental delay to objects and situations that cause fear); 3) the stage of comparison - the purpose of the stage an empirical study of psychological characteristics, behavioral characteristics and general emotional background of older preschool children with mental developmental delay, which are mainly used as strategies for dealing with age fears.

The results of the empirical study showed that:

1) the presence of natural age fears is characteristic of the vast majority of older preschool children with mental developmental delay;

2) the spectra and degree of distribution of certain natural age fears are quite typical, and approximately the same;

3 ) these spectra of fears and their quantitative ratio change with the change of social and information situation in society;

4) for modern older preschoolers with mental developmental delay, the existential fear of death gives way to fears of violent death (on the one hand - due to saturation of media space available to children, and on the other - due to terrible virtual monsters, monsters, unnaturally large and amazing animals, spiders, birds, etc.);

5) the share of children's fears is occupied by social fears that have "rejuvenated" and diversified (for example, fear of rejection, fear of incompatibility, fear of helplessness, etc.).

\section{CONCLUSIONS}

Theoretical and empirical analysis of the importance of fear in the lives of older preschool children with mental developmental delay allowed us to draw the following conclusions. In contrast to everyday discourse, where fear appears mainly as a destabilizing, anxious and stressful factor, in scientific discourse fear has much more meaning. It is considered as a basic human emotion necessary for its normal 
functioning and development, which at different ages of human life performs many important life-saving, psychological, social, inculturational and other functions that can be integrated into three main groups: 1) functions of adaptation and protection (physical, psychophysiological, psychological, psychosocial); 2) the functions of education and socialization; 3) the functions of personal development and «humanization».

As a basic emotion, fear is actualized in the first years of human life (a child with mental developmental delay) and is manifested: 1) as typical emotional, cognitive and behavioral reactions of the child to stimuli and situations that actualize fear and its sources; 2) as natural age fears of a child with mental developmental delay of a certain age, which have a certain object and come from specific sources and are quite typical for most children of infancy, early childhood and preschool age.

The range of natural fears of older preschool children with mental developmental delay and ways of responding to them, namely strategies for dealing with these fears, are quite typical for most older preschool children with mental developmental delay and depend relatively little on the child; features of its close and remote social environment and features of the social situation of its development as a whole. Typical age fears of older preschoolers with mental developmental delay are: 1) archaic, existential, vital fears, which are related to the preservation of life and occupy the "lion's share" among all others; 2) social fears that arise from the social nature of man and his basic social needs in different periods of adulthood and are associated with the risk of meeting these needs (these fears are activated in early preschool age and are one of the important psychological neoplasms of this age); 3) fears of a phobic nature, which acquire a pathological course and with which the child is unable to cope alone. A special, somewhat "artificial" type of fears of modern children are fears activated by screen media, which, in contrast to natural children's fears (which are able to self-initiate, relatively successfully live a child with mental developmental delay and disappear without special intervention by adults), more often need special attention from adults.

Along with the appearance of natural age fears, which from birth play an important role in the life of a child with mental developmental delay, the necessary strategies for their processing (or coping strategies) are also naturally updated. The whole set of these strategies is divided into two essentially different groups: 1) strategies of avoidance, or strategies of psychological protection (qualified by us as unproductive coping); 2) strategies for active processing and overcoming fear (or productive coping). Older preschoolers with mental developmental delay 
consciously or intuitively use different strategies and, thanks to which, they are able to overcome their fears relatively successfully on their own.

\section{SUMMARY}

In contrast to everyday discourse, where fear appears mainly as a destabilizing, anxious and stressful factor, in scientific discourse fear has much more meaning. The range of natural fears of older preschool children with mental developmental delay and ways of responding to them, namely strategies for dealing with these fears, are quite typical for most older preschool children with mental developmental delay and depend relatively little on the child; features of its close and remote social environment and features of the social situation of its development as a whole. A special, somewhat "artificial" type of fears of modern children are fears activated by screen media, which, in contrast to natural children's fears (which are able to self-initiate, relatively successfully live a child with mental developmental delay and disappear without special intervention by adults), more often need special attention from adults.

Along with the appearance of natural age fears, which from birth play an important role in the life of a child with mental developmental delay, the necessary strategies for their processing (or coping strategies) are also naturally updated.

Fear is a basic human emotion necessary for the formation and normal development of his psyche and successful socialization. At different ages of human life, fear performs a number of important psychological functions: mobilization, preventive, protective, socializing, strategic, etc. The first natural age fears are actualized at an early age, and with the child's growth they evolve in the direction from physiological to social, and also significantly depend on the social environment, close environment and social situation of the special child as a whole.

Psychological features of the fears of older preschoolers with mental retardation are primarily as follows: 1) most of these fears are natural and temporary; 2) their content is due to the age of the child; 3) the main sources of children's age fears are the nature of the child as a human being and the social environment in which he grows up; 4) with the actualization of age fears, the relevant mechanisms and strategies of their processing are automatically actualized, which at the very beginning have an involuntary and intuitive nature and are strategies of "common sense".

Typical age fears of older preschool children with mental retardation include: 1) archaic; 2) existential; 3) congratulatory fears; 4) fears of a phobic nature (which are somehow related to the protection and preservation of life); 5) fears that arise from the social nature of man and are related to basic social needs, which are activated in the senior 
preschool age. A special and to some extent «artificial» kind of fears of modern children are the so-called media fears, or fears activated by screen media. The child of the XXI century has to deal with such fears, which were not experienced by her peers of the XX century: they are caused, in particular, by horror movies, computer game characters, serial killers, militants with scenes of violence and murder, daily reports of terrorist acts in the media information. Unlike children's natural fears (which are able to initiate themselves, live relatively successfully as a child and disappear without special intervention), media fears require special attention from adults.

Along with natural age fears, a person, in particular a child of older preschool age with mental retardation, has adequate psychological resources for their development, which can be divided into two main groups: 1) protection resources and appropriate mechanisms and strategies for their implementation; 2) coping resources and appropriate mechanisms and strategies for active processing of fear, or coping strategies (behavioral, cognitive and emotional). Psychological protection and coping perform similar functions - they help a person at all ages of his life in dangerous, life threatening and well-being situations. However, protection strategies are a way to avoid and procrastinate, and coping strategies are to actively engage in circumstances, live productively, and gain new experience.

The peculiarity of coping strategies of older preschool children with mental retardation is not as relevant as their potential understanding, which is in the zone of their immediate development. The implementation of these strategies involves not so much rational as intuitive factors, the effectiveness of which is primarily explained not by considerations of logic, but by considerations of "intuitive expediency".

\section{References}

1. Assessment of behavioral and emotional problems in infancy: a systematic review / D. Bagner et al. Clinical Child and Family Psychology Review. 2012. P. 113-128.

2. Gurnani T., Ivanov I., Newcorn J. Pharmacotherapy of Aggression in Child and Adolescent Psychiatric Disorders. Journal of Child Adolescent Psychopharmacology. 2016. P. 65-73.

3. Kolko D., Perrin E. The integration of behavioral health interventions in children's health care: services, science, and suggestions. Journal of Clinical Child and Adolescent Psychology. 2014. P. 216-228.

4. Hong J., Tillman R., Luby J. Disruptive behavior in preschool children: distinguishing normal misbehavior from markers of current and later childhood conduct disorder. Journal of Pediatrics. 2015. P. 723-730. 
5. Ramsawh H., Chavira D., Stein M. Burden of anxiety disorders in pediatric medical settings: prevalence, phenomenology, and a research agenda. Archives of pediatrics and adolescent medicine. 2010. P. 965-972.

\section{Information about the authors:}

Panov M. S.,

Doctor in Psychology, Assistant Professor, Assistant Professor at the Department of Special Pedagogy and Special Psychology

Municipal Institution of Higher Education "Khortytsia National Educational Rehabilitation Academy" of Zaporizhzhia Regional Council 59, Naukove Mistechko str., Zaporizhzhia, 69017, Ukraine

Zhadlenko I. O.,

Ph. D. in Pedagogy, Associate Professor, Associate Professor at the Department of Special Pedagogy and Special Psychology Municipal Institution of Higher Education "Khortytsia National Educational Rehabilitation Academy" of Zaporizhzhia Regional Council 59, Naukove Mistechko str., Zaporizhzhia, 69017, Ukraine 